\title{
Optimal time of tumour response evaluation and effectiveness of hypofractionated proton beam therapy for inoperable or recurrent hepatocellular carcinoma
}

\author{
Tae Hyun Kim ${ }^{1, *}$, Joong-Won Park ${ }^{1, *}$, Bo Hyun Kim ${ }^{1, *}$, Dae Yong Kim ${ }^{1}$, Sung Ho \\ Moon ${ }^{1}$, Sang Soo Kim ${ }^{1}$, Ju Hee Lee ${ }^{1}$, Sang Myung Woo ${ }^{1}$, Young-Hwan Koh ${ }^{1}$, Woo \\ Jin Lee ${ }^{1}$ and Chang-Min Kim ${ }^{1}$ \\ ${ }^{1}$ Center for Liver Cancer, Research Institute and Hospital, National Cancer Center, Goyang, Korea \\ *These authors contributed equally to this work \\ Correspondence to: Tae Hyun Kim, email: k2onco@naver.com \\ Keywords: hepatocellular carcinoma; tumour response; proton beam therapy \\ Received: June 10,2017 Accepted: November 26, $2017 \quad$ Published: December 19, 2017 \\ Copyright: Kim et al. This is an open-access article distributed under the terms of the Creative Commons Attribution License 3.0 \\ (CC BY 3.0), which permits unrestricted use, distribution, and reproduction in any medium, provided the original author and source \\ are credited.
}

\section{ABSTRACT}

Objective: To evaluate the optimal time of tumour response and effectiveness of hypofractionated proton beam therapy (PBT) for hepatocellular carcinoma (HCC).

Results: Overall, treatment was well tolerated with no grade toxicity $\geq 3$. Of 71 patients, 66 patients $(93 \%)$ eventually reached complete response (CR) after PBT: 93.9\% (62 of 66) of patients who reached CR within 12 months, and the remaining 4 patients (6.1\%) reached $C R$ at $12.5,16.2,19.1$ and 21.7 months, respectively. The three-year local progression-free survival (LPFS), relapse-free survival (RFS) and OS rates were $\mathbf{8 9 . 9} \%, \mathbf{2 6 . 8 \%}$, and $\mathbf{7 4 . 4 \%}$, respectively. Multivariate analysis revealed that the tumour response was an independent prognostic factor for LPFS, RFS, and OS.

Conclusion: Most CR was achieved within 1 year after PBT and further salvage treatments in PBT field might be postponed up to approximately 18-24 months. Hypofractionated PBT could be good alternative for HCC patients who are unsuitable for surgical or invasive treatments with curative intent.

Materials and Methods: Seventy-one inoperable or recurrent HCC patients underwent hypofractionated PBT using 66 GyE in 10 fractions. The tumour responses were defined as the maximal tumour response observed during the follow-up period using the modified Response Evaluation Criteria in Solid Tumors criteria.

\section{INTRODUCTION}

Surgical resection, liver transplantation, and local ablative treatments, including radiofrequency ablation (RFA), are considered as curative treatment options for patients with hepatocellular carcinoma (HCC) [1]. Unfortunately, the use of surgical resection and liver transplantation are restricted to selected patients due to the multifocality of HCC development in cirrhotic livers, advanced tumours and/or comorbidities, including underlying liver cirrhosis (LC), and the shortage of graft donors. In addition, RFA is unsuitable for patients with bleeding tendency, unfavourable tumour location (i.e., proximity of lesions to the major vessels or gall bladder, and sub-diaphragmatic lesions), presence of a non-echogenic lesion, or large-sized tumours. For inoperable HCC patients unsuitable for local ablative therapies, although transcatheter arterial chemoembolisation (TACE) has a survival benefit compared with best supportive care $[2,3]$, its radical effects are limited histopathologically [4]. Thus, there seems to be a need for effective and less invasive local treatments in inoperable HCC patients ineligible for local ablative therapies.

Technological innovations in the field of radiotherapy (RT), such as three-dimensional conformal RT (CRT), intensity-modulated radiation therapy (IMRT), stereotactic body radiation therapy (SBRT), and proton beam therapy (PBT), could potentially deliver radiation more precisely to 
tumours while sparing the normal tissues [5-17]. Recently, hypofractionated CRT/IMRT with $\sim 10$ fractions or SBRT with 3-6 fractions have been attempted to reduce the treatment duration to be more convenient for patients and to increase the biologic effect of RT [9, 12, 14, 18-20]. Moreover, due to the distinct physical characteristics of proton beams and the Bragg peak in allowing deposition of high doses of radiation within the target and the lack of an exit dose outside the target, the role of charged particle therapy, including PBT, has been actively investigated [5-7, 13, 15, 16]. Conceptually, hypofractionated PBT can create a potential improvement in the therapeutic ratio compared with conventional fractionated PBT due to less repair of radiation damage of surrounding normal tissues and shortened overall treatment time. Based on this background, inoperable or recurrent HCC patients who failed or were unsuitable to local therapies have been treated at our institution by hypofractionated PBT. In addition, although several studies have reported that objective response gradually increased up to 1 year after SBRT and PBT $[5,9,21]$, to the best of our knowledge, the optimal time of tumour response evaluation after RT, including PBT, and impact of time interval between tumour response and RT has not been thoroughly evaluated by a long-term follow-up study. This information is important when deciding further salvage treatments after RT. This study was designed to retrospectively analyse the clinical outcomes of hypofractionated PBT in inoperable or recurrent HCC patients and to evaluate the optimal time of tumour response evaluation and clinical effectiveness of this method.

\section{RESULTS}

Patient characteristics are summarised in Table 1. The study included 60 men $(84.5 \%)$ and 11 women (15.5\%) with a median age of 63 years (range, 40-92 years). Sixty-eight patients were in Child-Pugh class A, and 3 patients were Child-Pugh class B. The AFP level ranged from 1.3 to $2732.2 \mathrm{ng} / \mathrm{mL}$ (median, $7.6 \mathrm{ng} / \mathrm{mL}$ ). All but 1 patient, who was treatment naïve due to refusal to surgical and nonsurgical treatments, had recurrent or residual tumour in the PBT site. Of the 71 patients, 55 $(77.5 \%)$ had a recurrent or residual tumour in the liver prior to PBT despite undergoing one or more interventions to PBT site, including TACE, RFA, and/or PEIT. The remaining 16 patients $(15.5 \%)$ had not received any prior treatment to the PBT site due to the lack of indications for other treatment modalities (Table 1). After completion of PBT, additional treatments were not performed at the PBT site until tumour progression was confirmed.

The median follow-up duration was 31.3 months (range, 4.2-47 months). Of 71 patients, 66 patients (93\%) reached CR eventually (Figure 1). The remaining 5 patients $(7 \%)$ did not reach CR: SD in $1(1.4 \%)$ and $\mathrm{PD}$ in $4(5.6 \%)$. Of the 66 patients who reached CR, the mean time to CR was 6.3 months $(95 \%$ confidence interval [CI], 5.2-7.5 months) (range, 1-21.7 months): 18 patients $(27.3 \%)$ showed CR within 3 months, 44 patients $(66.7 \%)$ showed CR within 6 months, 57 patients (86.4\%) showed CR within 9 months, 62 patients (93.9\%) showed CR within 12 months, and remaining 4 patients (6.1\%) reached CR at 12.5, 16.2, 19.1 and 21.7 months after PBT, respectively. The actuarial CR rates at 3 months, 6 months, 9 months and 12 months were $21.3 \%$ (95\% CI, 11.7-30.9\%), 60\% (95\% CI, 48.4-71.6\%), 81.8\% (95\% CI, 72.6-91.0\%) and 89.4\% (95\% CI, 81.9-96.8\%), respectively (Figure 1). The distributions of clinical characteristics were not significantly different between the patients who reached CR and those who did not reach CR $(p>0.05$ each) (Supplementary Table 1$)$.

At the time of analysis, 16 patients died due to intrahepatic disease progression $(n=10)$, liver failure by progression of LC $(n=2)$, bone metastasis $(n=2)$, brain metastasis $(n=1)$, and pneumonia $(n=1)$, not related with treatment, and 55 remained alive. Of the 71 patients, $49(69 \%)$ developed disease recurrence, including 6 $(8.5 \%)$ with local progression, 49 (69\%) with intrahepatic recurrence, and $11(15.5 \%)$ with distant metastases (Supplementary Figure 1). The median time to local progression, intrahepatic progression, and distant metastasis was 13 months (range, 8.4-31.7 months), 9.9 months (range, 1.1-34.3 months), and 12.1 months (range, 7.7-32.5 months), respectively. After the diagnosis of disease recurrences, 47 of $49(95.9 \%)$ patients, except for 2 patients (combined with obstructive jaundice by progressive disease $[n=1]$, or progressive distant metastasis $[n=1]$ ), received salvage treatments to the PBT site and/or other sites, such as one or combinations of various locoregional treatments (i.e., TACE, RFA, PBT) and/or systemic treatments (i.e., sorafenib, doxorubicin, etc.). The actuarial 3-year LPFS, RFS and OS rates were 89.9\% (95\% CI, 81.8-98\%), 26.8\% (95\% CI, 14.9-38.7\%), and 74.4\% (95\% CI, 63.1-85.7\%), respectively (Figure 2). Local progression developed in 2 of 66 patients $(3 \%)$ who reached $\mathrm{CR}$ and 4 of 5 patients (80\%) who did not reach CR $(p<0.001)$. Of 66 patients who reached $\mathrm{CR}$, there was no significant differences in 3-year LPFS (97.6\% [95\% CI, 93.0-100\%] vs. 93.3\% [95\% CI, 80.7-100\%], $p=0.793)$, DFS (24.3\% [95\% CI, $6.8-41.8 \%$ ] vs. $32.1 \%$ [95\% CI, 12.9-51.4\%], $p=0.336)$, OS (80.4\% [95\% CI, 68.1-92.6\%] vs. 81.2\% [95\% CI, 64.5-97.9\%], $p=0.416$ ) rates between the patients who reached CR within 6 months after completion of RT and those who reached $\mathrm{CR}$ after 6 months. Before CR was reached in PBT site, intrahepatic progression was observed in 11 of 66 patients $(16.7 \%)$ who reached CR, was treated with local treatments, such as TACE $(n=8), \operatorname{RFA}(n=2)$, and combination of TACE and RFA $(n=1)$, and distant metastasis was not observed. Of 66 patients who reached $\mathrm{CR}$, there was no significant difference in 3-year LPFS rates (100\% vs. $94.8 \%, p=0.338)$ whether salvage treatments to other sites was given or not. Three-year LPFS (95.5\% vs. $0 \%, p<0.001)$, RFS $(28.3 \% \%$ vs. $0 \%, p=0.046)$, and OS 
Table 1: Patient characteristics

\begin{tabular}{|c|c|c|}
\hline Characteristics & & Total, $n(\%)$ \\
\hline \multirow[t]{2}{*}{ Gender } & Male & $60(84.5)$ \\
\hline & Female & $11(15.5)$ \\
\hline \multirow[t]{3}{*}{ Age, years } & Median (range) & $63(40-92)$ \\
\hline & $<60$ & $22(31.0)$ \\
\hline & $\geq 60$ & $49(69.0)$ \\
\hline ECOG PS & 0 & $71(100)$ \\
\hline \multirow[t]{4}{*}{ Aetiology of LC } & $\mathrm{HBV}$ & $57(80.3)$ \\
\hline & $\mathrm{HCV}$ & $5(7.0)$ \\
\hline & Alcoholic & $3(4.2)$ \\
\hline & unknown & $6(8.5)$ \\
\hline \multirow[t]{2}{*}{ Child-Pugh Classification } & $\mathrm{A}$ & $68(95.8)$ \\
\hline & $\mathrm{B}$ & $3(4.2)$ \\
\hline \multirow[t]{3}{*}{ AFP, ng/mL } & Median (range) & $7.6(1.3-2732.2)$ \\
\hline & $<10$ & $43(60.6)$ \\
\hline & $\geq 10$ & $28(39.4)$ \\
\hline \multirow[t]{3}{*}{ Tumour size, $\mathrm{cm}$} & Median (range) & $1.5(1.0-8.5)$ \\
\hline & $<3$ & $64(90.1)$ \\
\hline & $\geq 3$ & $7(9.9)$ \\
\hline \multirow[t]{3}{*}{ AJCC stage } & $\mathrm{I}$ & $15(21.1)$ \\
\hline & II & $51(71.8)$ \\
\hline & IIIA & $5(7.1)$ \\
\hline \multirow[t]{2}{*}{ BCLC stage } & $\mathrm{A}$ & $43(60.6)$ \\
\hline & $\mathrm{B}$ & $28(39.4)$ \\
\hline \multirow[t]{4}{*}{ Pre-Tx to PBT site } & No & $16(22.5)$ \\
\hline & Yes & $55(77.5)$ \\
\hline & TACE & $49(89.1)$ \\
\hline & TACE + RFA and/or PEIT & $6(10.9)$ \\
\hline \multirow[t]{5}{*}{ Pre-Tx to other site } & No & $11(15.5)$ \\
\hline & Yes & $60(84.5)$ \\
\hline & $\mathrm{TACE} \pm \mathrm{RFA} \pm \mathrm{PEIT}$ & $44(73.3)$ \\
\hline & $\mathrm{SR} \pm \mathrm{TACE} \pm \mathrm{RFA} \pm \mathrm{PEIT} \pm$ Sorafenib & $14(23.3)$ \\
\hline & RFA & $2(3.4)$ \\
\hline
\end{tabular}

Abbreviations: LC, liver cirrhosis; HBV, hepatitis B virus; HCV, hepatitis C virus; AFP, a-fetoprotein; ECOG, Eastern Cooperative Oncology Group; PS, performance status; AJCC, American Joint Committee on Cancer; BCLC, Barcelona Clinic Liver Cancer; Tx, treatment; PBT, proton beam therapy; TACE, transcatheter arterial chemoembolisation; RFA, radiofrequency ablation; PEIT; percutaneous ethanol injection treatment; and SR, surgical resection.

$(81.1 \%$ vs. $0 \%, p<0.001)$ rates were significantly increased in the patients who reached CR compared with those who did not. However, the 3-year LPFS, RFS, and OS rates were not significantly different whether pre-treatments to the PBT site or other sites were given or not (Table 2).

Univariate and multivariate analyses were performed to identify clinical parameters predicting LPFS, RFS, and OS (Tables 2 and 3, respectively).
Univariate analysis demonstrated that tumour response was significantly associated with LPFS and RFS and that Child-Pugh classification, AFP level, AJCC stage, and tumour response were significantly associated with OS $(p<0.05)$ (Table 2). In multivariate analysis, tumour response was a significant factor independently associated with LPFS and RFS ( $p<0.05$ each). In addition, ChildPugh classification, AJCC stage and tumour response 
were significant factors independently associated with OS $(p<0.05$ each) (Table 3$)$.

Overall, treatment was well tolerated with no patient experiencing grade $\geq 3$ toxicity. Within 3 months after PBT, acute toxicities were transient, easily manageable, and caused no interruption in treatment course. Of the 71 patients, $62(87.3 \%)$ showed no change in Child-Pugh score, six $(8.5 \%)$ showed a 1-point decrease and three $(4.2 \%)$ showed a 1 -point increase. Three $(4.2 \%)$ patients experienced grade 1 elevated ALT without evidence of tumour progression, and six $(8.5 \%)$ patients experienced grade 1 leukopenia and thrombocytopenia. After 3 months after PBT, no late gastrointestinal toxicities defined as gastric or duodenal ulcers within the RT field, late hepatic failure induced by radiation-induced liver disease or treatment-related death was observed.

\section{DISCUSSION}

The optimal time of response evaluation after RT for HCC has not been well-defined. Price et al. [21] analysed 26 HCC patients treated with SBRT using 24-48 Gy in
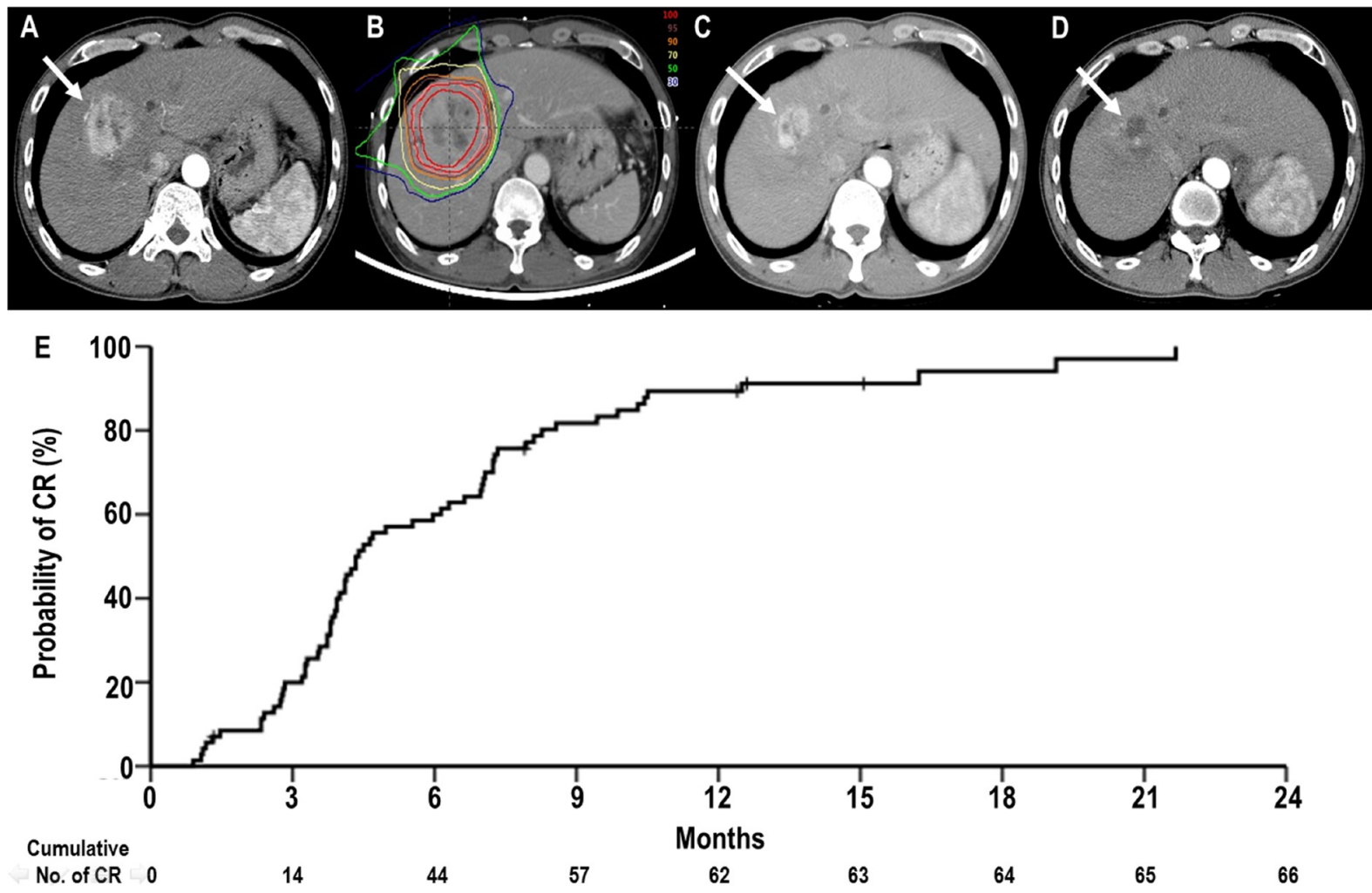

Figure 1: Complete response (CR) of a primary tumour to proton beam therapy (PBT). (A) Pretreatment CT scans showing the primary tumour (arrow). (B) The patient underwent PBT. (C) CT scans at 3 months after PBT demonstrating shrinkage of the primary tumour (arrow). (D) CT scans at 8 months after PBT demonstrating complete regression of the primary tumour (arrow). (E) The actuarial CR curves of primary tumour after PBT.

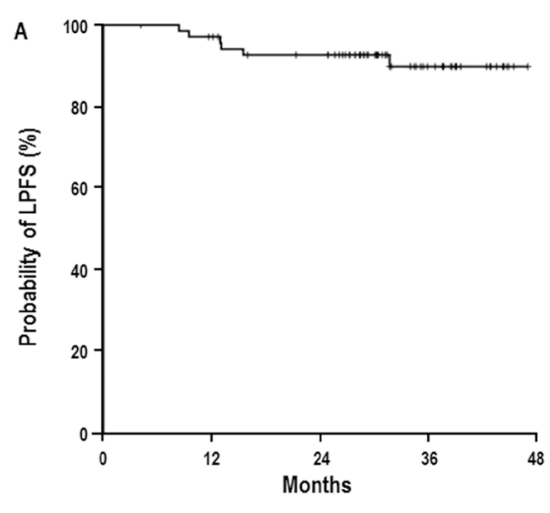

No. at risk 71

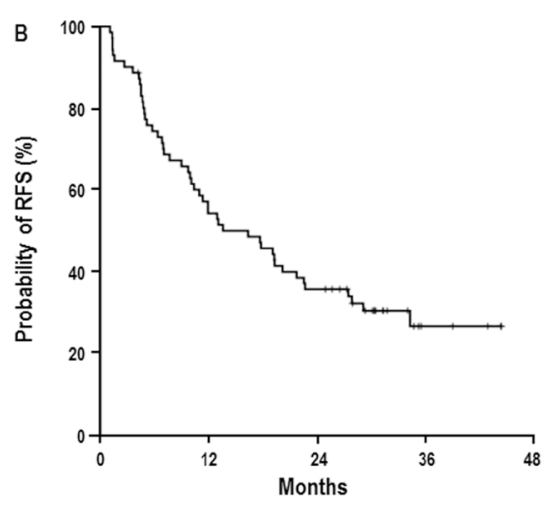

No. at risk 71

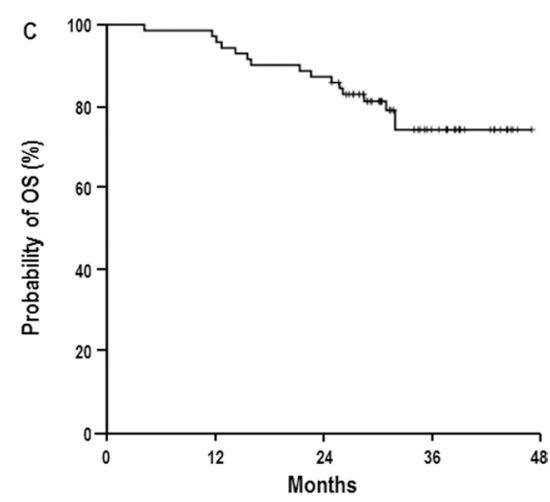

No. at risk $71 \quad 69 \quad 62 \quad 24 \quad 0$

Figure 2: Local progression-free survival (LPFS) (A), relapse-free survival (RFS) (B), and overall survival (OS) (C) curves in all patients. 
Table 2: Univariate analysis of clinical characteristics associated with local progression-free survival (LPFS), relapsefree survival (RFS), and overall survival (OS)

\begin{tabular}{|c|c|c|c|c|c|c|c|c|}
\hline \multirow[b]{2}{*}{ Characteristics } & & \multicolumn{3}{|c|}{ LPFS } & RFS & \multicolumn{3}{|c|}{ OS } \\
\hline & & No. of patients, $n$ & 3 year $(95 \% \mathrm{CI}), \%$ & $p$-value ${ }^{\dagger}$ & 3 year $(95 \% \mathrm{CI}), \%$ & $p$-value ${ }^{\dagger}$ & 3 year $(95 \% \mathrm{CI}), \%$ & $p$-value ${ }^{+}$ \\
\hline \multirow[t]{2}{*}{ Gender } & Male & 60 & $87.8(78.1-97.5)$ & 0.273 & $21.9(6.6-37.2)$ & 0.896 & $72.6(59.7-85.5)$ & 0.694 \\
\hline & Female & 11 & $100(100)$ & & $36.4(8.0-64.8)$ & & $81.8(59.0-100)$ & \\
\hline \multirow[t]{2}{*}{ Age, years } & $<60$ & 22 & $89.5(79.2-99.8)$ & 0.879 & $21.8(4.1-39.5)$ & 0.387 & $81.8(65.7-97.9)$ & 0.589 \\
\hline & $\geq 60$ & 49 & $90.7(78.4-100)$ & & $28.8(13.4-44.2)$ & & $71.3(60.0-85.6)$ & \\
\hline \multirow[t]{2}{*}{ Aetiology of LC } & HBV & 57 & $87.3(77.2-97.4)$ & 0.214 & $24.3(11.6-37.0)$ & 0.497 & $71.4(58.2-84.7)$ & 0.445 \\
\hline & Others & 14 & $100(100)$ & & $38.7(12.2-65.2)$ & & $85.7(67.4-100)$ & \\
\hline \multirow[t]{2}{*}{ Child-Pugh Classification } & $\mathrm{A}$ & 68 & $89.6(81.3-97.9)$ & 0.665 & $27.5(15.3-39.7)$ & 0.051 & $76.4(65.1-87.7)$ & 0.034 \\
\hline & $\mathrm{B}$ & 3 & $100(100)$ & & $0(-)$ & & $33.3(0-86.6)$ & \\
\hline \multirow[t]{2}{*}{ AFP, $n g / m L$} & $<10$ & 43 & $88.8(77.9-99.7)$ & 0.882 & $33.7(19.6-48.2)$ & 0.098 & $84.2(72.2-96.2)$ & 0.032 \\
\hline & $\geq 10$ & 28 & $92.1(82.1-100)$ & & $17.0(0-34.6)$ & & $60.0(39.8-80.2)$ & \\
\hline \multirow[t]{2}{*}{ Tumour size, $\mathrm{cm}$} & $<3$ & 64 & $88.8(80.0-97.7)$ & 0.426 & $24.6(11.6-37.6)$ & 0.413 & $74.6(62.6-86.6)$ & 0.697 \\
\hline & $\geq 3$ & 7 & $100(100)$ & & $42.9(6.4-79.6)$ & & $71.4(38.0-100)$ & \\
\hline \multirow[t]{2}{*}{ AJCC stage } & I-II & 66 & $89.3(80.8-97.8)$ & 0.534 & $25.9(13.2-38.4)$ & 0.658 & $77.8(66.7-88.9)$ & 0.030 \\
\hline & IIIA & 5 & $100(100)$ & & $30.0(0-76.8)$ & & $30.0(0-76.8)$ & \\
\hline \multirow[t]{2}{*}{ BCLC stage } & A & 43 & $91.3(81.5-100)$ & 0.447 & $24.0(8.8-39.3)$ & 0.899 & $82.0(69.6-94.4)$ & 0.090 \\
\hline & $\mathrm{B}$ & 28 & $88.6(76.4-100)$ & & $29.9(10.9-48.8)$ & & $61.6(40.3-82.9)$ & \\
\hline \multirow[t]{2}{*}{ Pre-Tx to PBT site } & No & 16 & $88.9(68.4-100)$ & 0.647 & $31.3(8.6-54.0)$ & 0.817 & $93.8(81.9-100)$ & 0.087 \\
\hline & Yes & 55 & $90.4(82.4-98.4)$ & & $25.7(11.7-39.6)$ & & $68.7(91.9-82.5)$ & \\
\hline \multirow[t]{2}{*}{ Pre-Tx to other site } & No & 11 & $90.9(73.9-100)$ & 0.930 & $54.6(25.2-84.0)$ & 0.073 & $81.8(59.0-100)$ & 0.749 \\
\hline & Yes & 60 & 89.8 (80.9-98.7) & & $22.5(10.5-34.5)$ & & $73.5(61.2-85.8)$ & \\
\hline \multirow[t]{2}{*}{ Tumour response } & $\mathrm{CR}$ & 66 & $95.5(89.1-100)$ & $<0.001$ & $28.3(15.8-40.9)$ & 0.046 & $81.1 \%(70.6-91.5)$ & $<0.001$ \\
\hline & Non-CR & 5 & $0(-)$ & & $0(-)$ & & $0(-)$ & \\
\hline
\end{tabular}

Abbreviations: CI, confidence interval; CR, complete response; all others are the same as in Table 1.

$\dagger \log$-rank test.

Table 3: Multivariate analysis of clinical characteristics associated with local progression-free survival (LPFS), relapse-free survival (RFS), and overall survival (OS)

\begin{tabular}{|c|c|c|c|c|c|c|c|}
\hline \multirow{2}{*}{ Characteristics } & & \multicolumn{2}{|l|}{ LPFS } & \multicolumn{2}{|l|}{ RFS } & \multicolumn{2}{|l|}{ OS } \\
\hline & & Hazard Ratio (95\% CI) & $p$-value ${ }^{\dagger}$ & Hazard Ratio (95\% CI) & $p$-value ${ }^{\dagger}$ & Hazard Ratio (95\% CI) & $p$-value ${ }^{\dagger}$ \\
\hline \multirow[t]{2}{*}{ Child-Pugh Classification } & A & - & - & - & - & 1.000 & 0.017 \\
\hline & B & - & & - & & $\begin{array}{c}6.992 \\
(1.423-34.340)\end{array}$ & \\
\hline \multirow[t]{2}{*}{ AJCC stage } & I-II & - & - & - & - & 1.000 & 0.005 \\
\hline & IIIA & - & & - & & $\begin{array}{c}7.059 \\
(1.788-27.870)\end{array}$ & \\
\hline \multirow[t]{2}{*}{ Tumour response } & $\mathrm{CR}$ & 1.000 & $<0.001$ & 1.000 & 0.027 & 1.000 & $<0.001$ \\
\hline & Non-CR & 115.149 (12.300-1077.953) & & $3.392(1.148-10.026)$ & & $15.801(4.886-51.103)$ & \\
\hline
\end{tabular}

Abbreviations: same as in Tables 1 and 2.

${ }^{\dagger}$ Cox proportional hazards model. 
3-5 fractions and reported that the objective response $(\mathrm{CR}+\mathrm{PR})$ rates at 3 months, 6 months, 9 months, and 12 months were $59 \pm 8 \%, 69 \pm 8 \%, 81 \pm 8 \%$, and $92 \pm$ $7 \%$, respectively. Similarly, Kwon et al. [9] analysed 42 HCC patients treated with SBRT using 30-39 Gy in 3 fractions and reported that the mean time to achieve objective response was $5.1 \pm 3.7$ months. Kawashima et al. [5] analysed 30 patients treated with PBT using 76 GyE in 20 fractions and also demonstrated that 24 (80\%) patients achieved CR at 5-20 months (median, 8 months) after PBT. The present study analysed $71 \mathrm{HCC}$ patients treated with PBT using $66 \mathrm{GyE}$ in 10 fractions. The actuarial CR rates at 3 months, 6 months, 9 months, 12 months were $21.3 \%$ (95\% CI, 11.7-30.9\%), 60\% (95\% CI, 48.4-71.6\%), 81.8\% (95\% CI, 72.6-91.0\%) and 89.4\% (95\% CI, 81.9-96.8\%), respectively. The mean time to CR was 6.3 months (95\% CI, 5.2-7.5 months) (Figure 1). Of 66 patients who reached CR, 62 (93.9\%) showed CR within 12 months and remaining 4 patients (6.1\%) reached $\mathrm{CR}$ at $12.5,16.2,19.1$ and 21.7 months after PBT, respectively. The patients who reached CR had significantly higher 3-year LPFS rates compared with patients who did not reach CR $(95.5 \%$ vs. $0 \%, p<0.001)$. Considering these findings, evaluation of response might be performed every 3 months for the first year after completion of PBT. In cases which do not achieve a CR within 1 year, further salvage treatment could be postponed up to approximately 18-24 months after completion of PBT.

For HCC patients with a single tumour and wellpreserved liver function, surgical resection result in 5-year survival rates of $50-70 \%[1,22-24]$. As an alternative to surgical treatment, RFA has demonstrated satisfactory local tumour control of 70-90\% and a similar 5-year survival rate of $50-75 \%$ compared with surgical resection in patients with small $\mathrm{HCC}(\mathrm{s})<3 \mathrm{~cm}$ away from large vessels and Child Pugh class A [1, 24-26]. However, although RFA results in first CR in approximately $80 \%$ of $\mathrm{HCCs} \leq 3 \mathrm{~cm}$ in diameter, local progression was noted in $30-40 \%$ of patients with first CR experience, approximately $70 \%$ of patients with HCCs of 3.1-5 cm in diameter and all patients with HCCs $>5 \mathrm{~cm}[27,28]$. Recently, SBRT with 24-60 Gy in 3-6 fractions has been tried as an emerging non-invasive alternative to RFA and has demonstrated a similar 2- or 3 -year LPFS of 58-92\% and 2- or 3-year OS of 53-70\% compared with RFA $[9,12,14,18-21]$. Whal et al. reported no difference in 2-year LPFS (80.2\% vs. $83.8 \%, p>0.05)$ and OS $(52.9 \%$ vs. $46.3 \%, p>0.05)$ between patients treated with RFA and those with SBRT [11]. Similar to SBRT, PBT with 52.8-84 GyE in 4-34 fractions has been attempted for inoperable or recurrent $\mathrm{HCC}$ patients and has demonstrated a promising 2- or 3-year LPFS of 75-96\% and $45.1-66 \%[5,7,13,15,16,29]$. In the present study, we applied hypofractionated PBT with 66 GyE in 10 fractions and observed a 3-year LPFS rate of $89.9 \%$ and 3-year OS rate of $74.4 \%$. Although direct comparison of data among previous studies is difficult due to heterogeneous baseline characteristics, particularly regarding the degree of liver function impairment and tumour burden, in the present study, the LPFS and OS were comparable with outcomes of curative treatments, such as surgical resection and RFA, for HCC patients in our institutional cohort data [24] and other studies [1, 3, 11, 26, 27, 30]. In addition, multivariate analysis revealed that tumour response after PBT was a significant factor independently associated with LPFS, RFS, and OS ( $p<0.05$ each), suggesting that PBT could improve LPFS and subsequently RFS and OS. These findings suggest that PBT may have a major role in treatment of both favourable (small, solitary tumours and good liver functions) and difficult-to-treat cases of HCC, such as those with large or recurrent tumour(s) after additional curative treatments.

Similar to previous studies $[5,7,9,13,14,18$, $20,21,29]$, the major pattern of failure in the present study was intrahepatic recurrence outside the RT field $(69 \%)$ given the multifocal nature of HCC in the cirrhotic liver and high proportion (84.5\%) of intrahepatic disease outside of RT field in our study population. To enable further subsequent salvage treatment for residual or recurrent tumours after RT, such as TACE, sorafenib, RFA, surgery, and RT, it should be necessary to spare normal liver tissues to maintain remnant liver function. In a recent meta-analysis [16], survival rates for charged particle therapy were increased compared with those for CRT but similar to those for SBRT, and toxicity tends to be lower for charged particle therapy compared with CRT and SBRT. Similarly, our previous study demonstrated that better dose localisation properties of protons compared with photons made it possible to more effectively spare normal liver tissue in PBT compared with RT with photons [31]. Although the present study included several unfavourable prognostic characteristics (e.g., recurrent tumours and advanced stage), 47 of 49 (95.9\%) patients who had recurrent disease received post-PBT treatment to the PBT site and/or other sites; moreover, treatmentrelated toxicities were minimal, with no grade $\geq 3$ toxicity. These findings suggested that PBT could achieve local tumour control safely without influencing further salvage treatments for intrahepatic recurrence. However, because our data were obtained from a single institutional retrospective study with a relatively small population including small subgroup of Child-Pugh class $\mathrm{B}(n=3)$, the effects of local and systemic treatment for intrahepatic and/or metastatic disease, impact of remnant liver function, such as Child-Pugh Class B, and probable selection bias were not thoroughly evaluated. Thus, we initiated a phase III study to confirm the effectiveness and feasibility of PBT for HCC patients with recurrent or residual disease compared with RFA (NCCTS-13-695). 
In conclusion, most (94\%) patients achieved CR within 1 year after hypofractionated PBT, with median time to $\mathrm{CR}$ of about 6 months, and remaining $6.1 \%$ patients achieved CR at 12-22 months. There were no significant differences in LPFS, DFS and OS between the patients who reached CR within 6 months after completion of RT and those who reached CR after 6 months. These findings suggested that further salvage treatments in PBT field might be postponed up to approximately 18-24 months. Hypofractionated PBT exhibited feasible and promising outcomes in terms of LPFS and OS for inoperable or recurrent $\mathrm{HCC}$, which were comparable with outcomes of curative treatments, such as surgical resection or RFA, for HCC patients with early stage and well-preserved liver function. However, to accurately assess the optimal time of tumour response evaluation and effectiveness of hypofractionated PBT on LPFS, RFS, and OS compared with other local modalities, further larger and comprehensive studies are needed. However, our data suggested that hypofractionated PBT could be good alternative modality for HCC patients who are unsuitable for curative treatments, such as surgical resection or local ablative therapy.

\section{MATERIALS AND METHODS}

\section{Patients}

Between May 2013 and February 2015, a total of 71 patients with $\mathrm{HCC}$ receiving hypofractionated $\mathrm{PBT}$ who met the following criteria were included in this study: HCC was diagnosed by pathologic confirmation $(n=17)$ or on the basis of radiologic findings plus serum alphafetoprotein (AFP) concentrations $\geq 200 \mathrm{ng} / \mathrm{mL}(n=54)$ in accordance with the guidelines of the Korean Liver Cancer Study Group and the National Cancer Center [23]; gross tumour $\geq 2 \mathrm{~cm}$ from gastrointestinal structures; liver function of Child-Pugh class A or B; no active tumours outside the target volume; no history of previous RT to the target volume; no extrahepatic metastases; and no uncontrolled ascites. HCCs were classified according to the 2010 American Joint Committee on Cancer (AJCC) and Barcelona Clinic Liver Cancer (BCLC) [1] staging system and liver function was classified according to Child-Pugh classification. The study was performed in accordance with the guidelines of our institutional review board, which waived the requirement for informed consent due to the retrospective nature of the study.

\section{Pretreatment evaluation and treatment}

All patients underwent blood tests, including measurements of blood cell counts, liver and renal function tests, titres of hepatitis $\mathrm{B}$ and $\mathrm{C}$ virus (HBV and $\mathrm{HCV}$, respectively), and AFP. Abdominal dynamic contrast-enhanced CT and/or MRI was used to evaluate the extent of HCC. For RT planning, patients underwent CT simulation in a supine position with arms above the head and immobilised using an arm-up holder to improve setup reproducibility. Contrast-enhanced fourdimensional (4D) CT images were acquired with 2.5-mm slice thickness under shallow respiration using a 4D CT simulator (Light-Speed RT; GE Healthcare, Waukesha, WI, USA). During the 4D CT scan, the respiration signals of the patients were monitored by a real-time position management (RPM) system (Varian Medical Systems, Palo Alto, CA, USA). The acquired CT images were reconstructed in 10 equally spaced respiratory phases and, in the post-processing stage, maximum intensity projection (MIP), minimum intensity projection (MinIP), and average intensity projection (AIP) CT images were reconstructed using exhalation (gated) phases $(30 \%$ of total respiratory cycle) on an Advantage workstation (Version 4.3, GE Healthcare, Milwaukee, WI, USA). All 4D CT images were transferred to the Eclipse treatment planning system (Version 8.1; Varian Medical System, Palo Alto, CA, USA), and the contours for targets and organs at risk (OARs) were delineated in AIP-CT images during the exhalation (gated) phases. Figure 1 illustrates the definition of target volumes. The gross tumour volume (GTV) included all detectable primary tumours as determined by contrast-enhanced AIP-CT images during the exhalation phase, and the clinical target volume (CTV) was regarded as GTV [6-8, 10, 31, 32]. The gated internal target volume (ITV) was obtained by summing the GTVs in each CT image during the exhalation phases. The planning target volume included the ITV plus 5-7 mm margins in all directions. PBT planning was performed using 2-4 (median, 3) coplanar or non-coplanar beams of $230 \mathrm{MeV}$ protons (Proteus 235; Ion Beam Applications, S.A., Louvain-la-Neuve, Belgium) to cover the PTV. The beam energy and spread-out Bragg peak, which was defined as the distance between the distal and proximal $90 \%$ points of the maximum dose value, were fine-tuned so that the at least $95 \%$ of the PTV was encompassed by $100 \%$ of the prescribed dose, and the proximal, distal, border smoothing, smearing and aperture margins for proton beams using the double scattering mode to PTV were set to 5-7 $\mathrm{mm}$ each. The beam weights of the plan were optimised to minimise the maximal dose within the target volume and OARs. The dose was calculated for the target volume and OARs with heterogeneity corrections and expressed in Gray equivalents $[\mathrm{GyE}=$ proton physical dose (in Gray) $\times$ relative biologic effectiveness (1.1)]. The treatment was designed so that at least $95 \%$ of the PTV would receive $100 \%$ of each prescribed dose, and the equivalent dose in 2-Gy fractions (EQD2, GyE ${ }_{10}$ or $\mathrm{GyE}_{3}$ ) was calculated using a linear quadratic model with $\alpha / \beta$ ratios of 10 and 3 for acute and late effects on tumour and OARs, respectively. The prescribed dose of PTV was $66 \mathrm{GyE}\left(\mathrm{EQD} 2,91.3 \mathrm{GyE}_{10}\right)$ in 10 fractions based on results of our previous [6, 7] and other studies [29, 33]. 
The details of the normal tissue constraints have been described previously [6, 31]: the maximum dose to the spinal cord could not exceed $27 \mathrm{GyE}$; the relative volumes of the total and remaining normal liver that received doses

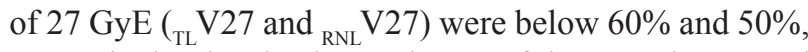
respectively; the absolute volumes of the oesophagus and stomach that received at least $37 \mathrm{GyE}$ were $\leq 2 \mathrm{~cm}^{3}$; and the absolute volumes of the small and large bowel that received at least $35 \mathrm{GyE}$ were $\leq 2 \mathrm{~cm}^{3}$. At each treatment fraction, digital orthogonal fluoroscopy was used to position patient and to verify the isocenter, and irradiation was performed during the exhalation phase using RPM system.

\section{Follow-up and statistical considerations}

Patients were assessed weekly during hypofractionated PBT and after completion of PBT at 1 month followed by every 2 to 3 months for the first 2 years and every 6 months thereafter. Follow-up evaluations consisted of a physical examination, a complete blood count, liver-function testing, chest radiography, and liver dynamic contrast-enhanced CT or MRI. The responses of the primary tumour were defined as the maximal tumour response observed during the follow-up period unless progression occurred as determined by comparing CT and/ or MRI scans before and after PBT using the modified Response Evaluation Criteria in Solid Tumors criteria (mRECIST) [34]. A complete disappearance of any intratumoural arterial enhancement in all target lesions was defined as a complete response (CR), a greater than 30\% decrease of viable (enhancing) target lesion was defined as a partial response (PR), and a greater than $20 \%$ increase of viable target lesion within in-field target volume or death before evaluation of response after treatment was defined as progressive disease (PD). Patients who did not meet the criteria for PR or PD were categorised as having stable disease (SD). Acute haematological and nonhaematological toxicities occurring within 3 months of PBT in the absence of disease progression were evaluated using Common Terminology Criteria for Adverse Events software version 3.0 (CTCAE v3.0).

Recurrence was proven pathologically by surgical resection, biopsy, or cytology and/or radiological findings showing an increase in size over time. Local progression was defined as a regrowth or new tumour within the treated volume. Intrahepatic recurrence was defined as a regrowth or new intrahepatic tumour outside the target volume. Distant metastasis was defined as lymph node recurrence, peritoneal seeding, or metastasis to extra-abdominal sites. Local progression-free survival (LPFS), relapse-free survival (RFS), and overall survival (OS) were defined as the intervals from the date of the start of PBT to the date of detection of local progression, any detection of recurrence, and death or last follow-up, respectively. OS rates were calculated using the Kaplan-Meier method. Univariate analysis of parameters predicting LPFS, RFS, and OS were assessed with log rank tests followed by multivariate analysis using Cox's proportional hazard model with a forward selection procedure containing factors of $p<0.1$ in univariate analysis. All statistical analyses were two-sided and were performed using STATA software (version 14.0; Stata Corp., College Station, TX, USA). A $p$-value $<0.05$ indicated statistical significance.

\section{Author contributions}

THK, JWP and BHK are responsible for the study design. THK, JWP, BHK, DYK, SHM, SSK, JHL, SMW, YHK, WJL and CMK collected the clinical data and drafted the manuscript. THK, JWP, BHK, DYK and CMK revised the manuscript. THK, SHM and SSK collected the pathologic data and analysis THK, DYK, JHL and YHK were responsible for the treatment and evaluation of the patients. SMW,WJL, BHK, DYK, JWP and THK provided oversight of the analysis of data and reviewing of the manuscript. All authors read and approved the final manuscript.

\section{CONFLICTS OF INTEREST}

None.

\section{GRANT SUPPORT}

This study was supported by National Cancer Center Grant (NCC 1710060 and 1710030).

\section{REFERENCES}

1. Llovet JM, Bru C, Bruix J. Prognosis of hepatocellular carcinoma: the BCLC staging classification. Semin Liver Dis. 1999; 19:329-338.

2. Llovet JM, Real MI, Montana X, Planas R, Coll S, Aponte J, Ayuso C, Sala M, Muchart J, Sola R, Rodes J, Bruix J, Barcelona Liver Cancer G. Arterial embolisation or chemoembolisation versus symptomatic treatment in patients with unresectable hepatocellular carcinoma: a randomised controlled trial. Lancet. 2002; 359:1734-1739.

3. Lo CM, Ngan H, Tso WK, Liu CL, Lam CM, Poon RT, Fan ST, Wong J. Randomized controlled trial of transarterial lipiodol chemoembolization for unresectable hepatocellular carcinoma. Hepatology. 2002; 35:1164-1171.

4. Higuchi T, Kikuchi M, Okazaki M. Hepatocellular carcinoma after transcatheter hepatic arterial embolization. A histopathologic study of 84 resected cases. Cancer. 1994; 73:2259-2267.

5. Kawashima M, Furuse J, Nishio T, Konishi M, Ishii H, Kinoshita T, Nagase M, Nihei K, Ogino T. Phase II study of radiotherapy employing proton beam for hepatocellular carcinoma. J Clin Oncol. 2005; 23:1839-1846. 
6. Kim DY, Park JW, Kim TH, Kim BH, Moon SH, Kim SS, Woo SM, Koh YH, Lee WJ, Kim CM. Risk-adapted simultaneous integrated boost-proton beam therapy (SIBPBT) for advanced hepatocellular carcinoma with tumour vascular thrombosis. Radiother Oncol. 2017; 122:122-129.

7. Kim TH, Park JW, Kim YJ, Kim BH, Woo SM, Moon SH, Kim SS, Koh YH, Lee WJ, Park SJ, Kim JY, Kim DY, Kim CM. Phase I dose-escalation study of proton beam therapy for inoperable hepatocellular carcinoma. Cancer Res Treat. 2015; 47:34-45.

8. Kim TH, Park JW, Kim YJ, Kim BH, Woo SM, Moon SH, Kim SS, Lee WJ, Kim DY, Kim CM. Simultaneous integrated boost-intensity modulated radiation therapy for inoperable hepatocellular carcinoma. Strahlenther Onkol. 2014; 190:882-890.

9. Kwon JH, Bae SH, Kim JY, Choi BO, Jang HS, Jang JW, Choi JY, Yoon SK, Chung KW. Long-term effect of stereotactic body radiation therapy for primary hepatocellular carcinoma ineligible for local ablation therapy or surgical resection. Stereotactic radiotherapy for liver cancer. BMC Cancer. 2010; 10:475.

10. Lee SU, Park JW, Kim TH, Kim YJ, Woo SM, Koh YH, Lee WJ, Park SJ, Kim DY, Kim CM. Effectiveness and safety of proton beam therapy for advanced hepatocellular carcinoma with portal vein tumor thrombosis. Strahlenther Onkol. 2014; 190:806-814.

11. Wahl DR, Stenmark MH, Tao Y, Pollom EL, Caoili EM, Lawrence TS, Schipper MJ, Feng M. Outcomes After Stereotactic Body Radiotherapy or Radiofrequency Ablation for Hepatocellular Carcinoma. J Clin Oncol. 2016; 34:452-459.

12. Bujold A, Massey CA, Kim JJ, Brierley J, Cho C, Wong RK, Dinniwell RE, Kassam Z, Ringash J, Cummings B, Sykes J, Sherman M, Knox JJ, et al. Sequential phase I and II trials of stereotactic body radiotherapy for locally advanced hepatocellular carcinoma. J Clin Oncol. 2013; 31:1631-1639.

13. Hong TS, Wo JY, Yeap BY, Ben-Josef E, McDonnell EI, Blaszkowsky LS, Kwak EL, Allen JN, Clark JW, Goyal L, Murphy JE, Javle MM, Wolfgang JA, et al. MultiInstitutional Phase II Study of High-Dose Hypofractionated Proton Beam Therapy in Patients With Localized, Unresectable Hepatocellular Carcinoma and Intrahepatic Cholangiocarcinoma. J Clin Oncol. 2016; 34:460-468.

14. Huertas A, Baumann AS, Saunier-Kubs F, Salleron J, Oldrini G, Croise-Laurent V, Barraud H, Ayav A, Bronowicki JP, Peiffert D. Stereotactic body radiation therapy as an ablative treatment for inoperable hepatocellular carcinoma. Radiother Oncol. 2015; 115:211-216.

15. Dionisi F, Widesott L, Lorentini S, Amichetti M. Is there a role for proton therapy in the treatment of hepatocellular carcinoma? A systematic review. Radiother Oncol. 2014; 111:1-10.

16. Qi WX, Fu S, Zhang Q, Guo XM. Charged particle therapy versus photon therapy for patients with hepatocellular carcinoma: a systematic review and meta-analysis. Radiother Oncol. 2015; 114:289-295.

17. Rim $\mathrm{CH}$, Seong J. Application of radiotherapy for hepatocellular carcinoma in current clinical practice guidelines. Radiat Oncol J. 2016; 34:160-167.

18. Sanuki N, Takeda A, Oku Y, Mizuno T, Aoki Y, Eriguchi T, Iwabuchi S, Kunieda E. Stereotactic body radiotherapy for small hepatocellular carcinoma: a retrospective outcome analysis in 185 patients. Acta Oncol. 2014; 53:399-404.

19. Seo YS, Kim MS, Yoo HJ, Jang WI, Paik EK, Han CJ, Lee BH. Radiofrequency ablation versus stereotactic body radiotherapy for small hepatocellular carcinoma: a Markov model-based analysis. Cancer Med. 2016; 5:3094-3101.

20. Yoon SM, Lim YS, Park MJ, Kim SY, Cho B, Shim JH, Kim KM, Lee HC, Chung YH, Lee YS, Lee SG, Lee YS, Park JH, et al. Stereotactic body radiation therapy as an alternative treatment for small hepatocellular carcinoma. PLoS One. 2013; 8:e79854.

21. Price TR, Perkins SM, Sandrasegaran K, Henderson MA, Maluccio MA, Zook JE, Tector AJ, Vianna RM, Johnstone PA, Cardenes HR. Evaluation of response after stereotactic body radiotherapy for hepatocellular carcinoma. Cancer. 2012; 118:3191-3198.

22. Korean Liver Cancer Study G, National Cancer Center K. 2014 Korean Liver Cancer Study Group-National Cancer Center Korea practice guideline for the management of hepatocellular carcinoma. Korean J Radiol. 2015; 16:465-522.

23. Korean Liver Cancer Study Group and National Cancer Center, Korea. [Practice guidelines for management of hepatocellular carcinoma 2009]. [Article in Korean]. Korean J Hepatol. 2009; 15:391-423.

24. Kwak HW, Park JW, Nam BH, Yu A, Woo SM, Kim TH, Kim SH, Koh YH, Kim HB, Park SJ, Lee WJ, Hong EK, Kim CM. Clinical outcomes of a cohort series of patients with hepatocellular carcinoma in a hepatitis B virusendemic area. J Gastroenterol Hepatol. 2014; 29:820-829.

25. Lin SM, Lin CJ, Lin CC, Hsu CW, Chen YC. Randomised controlled trial comparing percutaneous radiofrequency thermal ablation, percutaneous ethanol injection, and percutaneous acetic acid injection to treat hepatocellular carcinoma of $3 \mathrm{~cm}$ or less. Gut. 2005; 54:1151-1156.

26. Livraghi T, Goldberg SN, Lazzaroni S, Meloni F, Solbiati L, Gazelle GS. Small hepatocellular carcinoma: treatment with radio-frequency ablation versus ethanol injection. Radiology. 1999; 210:655-661.

27. Lopez PM, Villanueva A, Llovet JM. Systematic review: evidence-based management of hepatocellular carcinomaan updated analysis of randomized controlled trials. Aliment Pharmacol Ther. 2006; 23:1535-1547.

28. Sala M, Llovet JM, Vilana R, Bianchi L, Sole M, Ayuso C, Bru C, Bruix J, Barcelona Clinic Liver Cancer G. Initial response to percutaneous ablation predicts survival in 
patients with hepatocellular carcinoma. Hepatology. 2004; 40:1352-1360.

29. Fukumitsu N, Sugahara S, Nakayama H, Fukuda K, Mizumoto M, Abei M, Shoda J, Thono E, Tsuboi K, Tokuuye K. A prospective study of hypofractionated proton beam therapy for patients with hepatocellular carcinoma. Int J Radiat Oncol Biol Phys. 2009; 74:831-836.

30. Lencioni R. Loco-regional treatment of hepatocellular carcinoma. Hepatology. 2010; 52:762-773.

31. Kim JY, Lim YK, Kim TH, Cho KH, Choi SH, Jeong H, Kim DW, Park JH, Shin DH, Lee SB, Kim SS, Kim JY, Kim DY, et al. Normal liver sparing by proton beam therapy for hepatocellular carcinoma: Comparison with helical intensity modulated radiotherapy and volumetric modulated arc therapy. Acta Oncol. 2015; 54:1827-1832.
32. Kim TH, Kim DY, Park JW, Kim SH, Choi JI, Kim HB, Lee WJ, Park SJ, Hong EK, Kim CM. Dose-volumetric parameters predicting radiation-induced hepatic toxicity in unresectable hepatocellular carcinoma patients treated with three-dimensional conformal radiotherapy. Int J Radiat Oncol Biol Phys. 2007; 67:225-231.

33. Kanemoto A, Mizumoto M, Okumura T, Takahashi H, Hashimoto T, Oshiro Y, Fukumitsu N, Moritake T, Tsuboi K, Sakae T, Sakurai H. Dose-volume histogram analysis for risk factors of radiation-induced rib fracture after hypofractionated proton beam therapy for hepatocellular carcinoma. Acta Oncol. 2013; 52:538-544.

34. Lencioni R, Llovet JM. Modified RECIST (mRECIST) assessment for hepatocellular carcinoma. Semin Liver Dis. 2010; 30:52-60. 